\title{
Arabization and Its Effect on the Arabic Language
}

\author{
Abeer Obeid Al-Shbiel \\ Irbid University College, Al-Balqa Applied University (BAU), Jordan
}

\begin{abstract}
The present study aimed to explore the phenomenon of Arabization from foreign languages into the Arabic language where the study defined the concepts of Arabization in language and terminology, discussed the history of the concept through the history of the human civilization, discussed images of Arabization through three axes, namely: language borrowing, figurative translation, bending and compounding and their impact on the development of the contemporary Arabic language, identified the conditions of Arabization and referred to the efforts of the Academy of the Arabic Language in developing the Arabic language to cope with the modern scientific development; the study concluded a set of recommendations that concern the official planners and researchers in the field of the Arabic language.
\end{abstract}

Index Terms - Arabization, language borrowing, figurative translation, blending and compounding

\section{INTRODUCTION}

Arabizationis essential for our scientific life at the level of the Arab world because science is on the rise and it is continuously developing, so it should be accompanied with scientific, technical, industrial, political, literary, economic and military terms and names; therefore, it is not absurd to find many Arabized words in our Arabic dictionaries now and in the past noting that Arabization is a civilized need the Arabic language cannot live without since sciences are mutual among the world languages, which is permitted and needed.

Arabizationis no longer a developed process in the modern erawhere the Arabs in the state of Ignorance Arabizedterms like "a'lfulful"-"pepper", "A'lqurunful"- "cloves" from the Persian language, "Alsanajnajal"- "mirror" from the Roman language. In the Qur'an, there are some arabized words, such as: sajil, mishqah, abariq, and istabraq. One of the Arabized words in the Abbasid period is (Almajasti), which is the most ancient book in the astronomy of Ptolemy of Alexandria, and it was translated from Greek into Arabic by Izhaq Ben Hanin (Al-Mubarak,1989).

The researcher sees that it is important to pay attention to this phenomenon due to its importance on the linguistic level and the global civilization level as well as the need of our generations for this process to reach to the progress of civilizations in all fields leading to achieving the desired objectives and goals in modernization and development.

\section{Concept of Arabization: Language And TERMinology}

Arabizationin language: it is derived from the root "aruba" meaning "speaking eloquently after having an accent"; "arubat a'lmar'atu- "the woman was Arabized" means that she made love to her husband". "a'rba' Arabs" (Ibrahim Anis et al., Al-waseet Dictionary, Aruba); it also means "explaining and disclosure". The arabicization of any foreign name means that Arabs spell it according to their curricula and tongue (Al-Zubaidi, 1994). Al-Jawhari says ("ta'arrab", "Arabicize" means "to be similar to Arabs"; "he was Arabized after emigration "means"he became an Arab". "His tongue was Arabized" means "he became an Arab" and "Arabizinga foreign name" means that Arabs utter it according to their methods;(Al-Jawhari, 1979) which is consistent with Al-Bustani in stating that Arabization is uttering the foreign word as Arabs do making it Arabic. (Al-Bustani, 1995).

In terminology, Arabization means: the transfer of the foreign word and its meaning into Arabic according to rules and bases guaranteeing its clarity and eloquence; (Gahnim, 1989). "mu'arab" or "Arabized" is a term used by Arabs consisting of terms of meanings in other language; Aljawaliqi (d. $540 \mathrm{AH}$ ) sees that the Arabized word is "foreign speech spoken by the Arabs and pronounced by the Quran. It was mentioned in the news of the prophetpeace be upon him, companions and followers; it was also mentioned by Arabs in their poems and news to distinguish between the obvious and the foreign (Al-Jawaliqi, 1995). We can also say that Arabization is dying the word with an Arabic dye when being transformed with its foreign form into Arabic. (Anis, 1985).

It is concluded that the term arabization in language and terminology revolves around many different meanings: disclosure, explanation, no formation of words by violating the grammar, syntax, eloquence, sound and significance of the language.

\section{ARABiZATION IMPORTANCE}

Arabs have been affected by other nations through geographical nearness, economic and trade communication and Islamic wars leading that the words of such nations travelled to Arabic as other Arabic words moved to the languages of 
such nations affected by Arabs. Arabizationwas the last resort in transmitting from other languages into Arabic when there is no Arabic word to which the foreign word can be translated or when there is no word to which a verb or noun can be derived (Eisa, 1923). Arabs resorted to Arabization when their lives and culture expanded and started to contact the neighboring nations that new terms were moved into Arabic which were called the Arabized words by Arab scientists; in their travels, Arabs come into contact with other languages that some foreign words were introduced to their Arabic langue after some letters were deleted; such words were used in discussions and poetry; they were treated as classical Arabic language. (Khalifa, 1992).

The Arabization of modern science and technology is one of the pillars of the development of the country to keep up with the civilization and the creative, effective participation in all the fields of Knowledge; therefore, scientific institutions were established to discuss the issues and problems that can facilitate the historical movement in our nations where the Arab language becomes the language of modern sciences and technology as well as the language of research and teaching at Universities at different branches of knowledge (Khalifa, 1992); (Al Qassimi ,1986) said: "The researcher can measure the progress of the nation culturally, and identify the features of its culture through creed and counting their linguistic terminology; however, he can state the political and cognitive unity of the nation through the unity of its linguistic terms in humanities, science and technology" (Al- Qasimi, 1986); language is an essential component of the components of the nations' identities"(Ibrahim, 1994).

The importance of Arabization lies in : Kharyoush,( 2003):

1. Contributing to the enrichment of the Arabic language in the fields of the scientific terminology, symbols and specialized dictionaries.

2. Contributing to the enrichment of the Arabic language with scientific books written in an eloquent Arabic tongue.

3. Developing the spirit of creativity and composition for students since receiving science.

4. Arabization provides us with modern scientific terms indispensable in its scientific development; it enriches the language with words expressing all human meanings (Khalifa, 1992).

The live language interacts with other languages through giving and taking; accordingly, the presence of foreign words in language is for granted; therefore, this process should be mastered through experienced researchers. (Hugh, 1990)

The Arabization of sciences is not related to the nature of the language, or its ability for absorption. Arabization is a process of refining an external word according to the weights and structure of the Arabic language, dying a foreign word with Arabic, or forming a foreign word with Arabic letters when transferred, so Arabs can utter them according to language; Arabic has the superior ability to represent and arabize foreign words according to its mold, which is one of the most specific characteristics (Al-Thaalibi, 1999). The Arabic language has letters, verbs, grammar, poetry and certain characteristics that distinguished it. Having some foreign words added a special beauty and glamor to the language not affecting its essence or identity. (Khalifa, 1992)

In stressing the role and importance of Arabization, Al-Mubarak says that changing some sounds of foreign words when Arabicizing them through deleting un-Arabic words or adding the word's weight with one of its weights may be breeding or trimming since Arabic has a coherent and harmonized system pulled together in which words go on a special format in its letters, sounds, formulations, body and structure. (Al-Mubarak, 1968)

The Arabized word is "a word borrowed by the Arabic languagefrom other languages subjecting it to its vocal and morphological system through adding, subtracting or alternating it through substituting some Arabic letters with its letters." (Al Qasimi, 2004).

\section{Arabization of SCIENTIFiC AND TeChNiCAL TERms}

The Arabic language's need for the scientific and technical terms is an agreed-upon issue among the Arab linguists in spite of the differing views and interpretations in solving this problem, which is one of the biggest problems of the Arabic language in the present era (Faisal, 1986).

The issue of the scientific and technical term is a need that must be pursued to realize the purpose connected with the identity of the cultural nation, and spreading modern science (Al-Samarrai, 1982) specially that launching the scientific term in Arabic is one of the targets looked for by the Academy of the Arabic Language to achieve (Al-zarkan, 1998) through the cultural treaty for the year (1945) of Arabization and translation among the Arab countries, which stipulates that uniting terms goes only to the language academies, conferences, joint committees, and brochures published by the bodies; in (1964) the cultural unity Charter which was approved by the Academy of the Arabic Language focused on the need to strive to unite the scientific and cultural terms and support the Arabization movement (Ghazal, 1977); Furthermore, Ali Al Qassimi states: "the primary objective of providing unified Arab terminology is to find an Arab common scientific languageunderstood by all scientists and technicians in various Arab countries making it an effective tool for education, research, writing, and translation in the field of science and modern technology " (Al Qasimi,1986).

The conditions of translating the scientific term by the Arab scholars are as follows (Al-Mala'ika, 1974):

1. There must be a precise relationship between the original meaning and the new meaning.

2. In setting the term, attention with the accuracy of the meaning must be taken care of before the word itself.

3. The term must not be chosen from the terms with common and known original connotations.

4. Not using one word for indicating different scientific meanings and setting one word to denote a particular term. 
5. Notsetting different meanings for one scientific meaning to prevent distracting the mind of the educated; the new term should be agreed on among the Arab linguists.

6. Avoidingwords of difficult pronunciation or of fluctuating meaning due to its weight on the tongue, or filthy significance.

In his book, Sibawayh says, "they change letters that are not taken from the original language; they may attach (the foreign word) with their speech or not; they may leave the noun as is if its letters are the same as theirs either if it was built on their structure or not and finally they may change the letter which is not among their letters and that they did not change it when constructing it."(Sibawayh, 1983).

\section{Arabization ObStacles}

Despite the fact that Arabizationis governed by minute rules and regulations as a result of the effort put forth by the top linguists, there are some obstacles facing it, including:

1. Differentmethods and criteria of Arabizationin the Arab countries.

2. TheArabization of the university education in the Arab Universities, which is currently considered one of the serious issues where all the Arab universities, with the exception of the universities in Syria, teach many sciences in foreign languages.

\section{IMAGES AND MEANS OF ARABIZATION}

The means by which the arabization can be used mainly in to form new words to refer to new meanings are summarized in the following methods: (Ghanim, 2014):

- Linguistic borrowing.

- Figurative translation.

- Blending.

The following is the most prominent images of arabization used now and in the past.

\section{Linguistic Borrowing:}

The linguistic borrowing is one of the linguistic phenomena that received the attention of linguists; it is the process where a language takes some of the linguistic elements of another language, and attempts to copy a similar picture of the linguistic pattern of a language into another.

Alwaseet dictionary defines it as: adding or borrowing words from one language into another (Anis, 1985), which is metaphorical because of the fact that borrowing entails that the individual takes a thing to benefit from it for a while and then return it to the owner.

However, borrowing among languages is not the same since it is illogical that you borrow a certain term from a language and do not give it back. What is meant here is that the arabized and borrowed terms added to the dictionary in the vocabulary of foreign languages. (Wafi, 2004). Borrowing has happened through interaction and communication among nations (Wafi, 2010); Arabs were great and scattered tribes everywhere; so, they interacted with the Persians, Indians and Greek; one of the results of this mixture is that Arabic replaced Persian, Armenian in Iraq and Coptic in Egypt (Al-Suyouti, 1986).

We cannot say that borrowing is limited to Arabic; it is entitled to any language meant to evolve and grow. The Persian was affected by Arabic and the Persian dictionaries were affected by forty percent of the Arabic language that its dictionaries include many Arabic words. (Al-Tunaji, 1998). The linguistic borrowing is a phenomenon dispensable by any language; however, there can be some risks resulting from it, some of which include:

1. Loss of the expressive value of the Arabic root.

2. Ambiguity in the borrowed meaning in our dictionaries.

3. Difficulty in controlling the Arabized term.

4. Breaching the Arabic morphological rules.

5. Loss of the Arabic identity because of the linguistic colonialism that Ibn Khaldun saw that the nature is that losers imitate the victorious even in his own language, as we see today.

6. The linguistic colonialism might lead to other serious types of colonialism such as: the social colonialism which imitates the colonizer in his habits, clothing, and values, and the economic colonialism through heading to buy its products reaching to the cultural and religious colonialism through being colonized in everything.

Borrowing with its two parts: The Arabized and the foreign has a significant impact on civilization since that the emergence of terms in the fields of the economy, industry and commerce and philosophy has enrichedthe terms of the Arabic dictionary even that dictionaries specialized in economy, politics and philosophy emerged such as: dictionaries of scientific, engineering, philosophical and political terms...etc.

The researcher believes that borrowing is not a difficult process if confronted by specialists and those faithful from the people of the Arab nation, who are always there in every age; it with setting the accurate linguistic standards; God Himself save the Arabic language through guaranteeing His glorious book, Quran in: " We have, without doubt, sent down the Message; and We will assuredly guard it (from corruption)." (Al-Hijr 9).

2. Figurative Translation: 
Figurative translation: it is the translation of a term from one meaning to another which both share a certain semantic aspect. The meaning of a term may change from an era to another as a result of the social change. Some terms include: "'Almajd-glory", "alwagha- battlefield -" and "alghoufran-forgiveness" (Wafi, 2010). Figuration means naming a thing with another name; it is a method of expanding in the language derived from the language itself and it is beneficial for its verbal elements; the old nouns can be updated to refer to modern meanings in the methods of figurative translation.

The figurative translation depends on the linguistic context in determining the term and preferring it to other terms, which is one of the properties of the Arabic language known as the antonyms (words of the same structure and different meaning). The term is used until the figurative meaning becomes the one targeting the mind; Almubarrad says: "an example of the terms of the same structure and different meaning is "wajadtu-found" in: "I found a thing" meaning I found a thing I lost and "I found Zaid generous" meaning I learned that he is generous (Al-Daqiqi, 1985).

Thus, we find that the figurative translation is another form of Arabization by analogy, metaphor, or metonymy, which is a common method among sciences.

\section{Blending and Compounding:}

Nihad Moosa defines blending as: making a new word through two words or more, which are different in meaning and structure; the new word takes the form and the meaning; it isa form of transferring foreign words which do not have any equivalent in Arabic. (Al-Mousaq, 1990)

Linguists' opinions regarding this context vary; some find that blending enriches the Arabic language and they find it an indispensable means in the modern Arabic language and a method ensuring keeping up with the civilization and its sciences (Al-Saleh, 2004).

Others see that there is no need for blending since it is a stranger aspect in the Arabic language arguing that the ancient linguists did not consider it a form of derivation (Al-Mubarak, 1989).

Contemporary researchers focused on the importance of considering blending a standard aspect and that it should be used in the modern sciences; however, some are hesitant in accepting its scale and only listen without any other action (Abbas, 1966). There is a team of translators who sees the necessity that the Arabized word should follow an Arabic weight to be adopted in measurement with equivalents in language; it is not enough that the Arabs speak colloquial words to be considered Arabized. The other team, including Sibawayh and some other linguists sees that Arabization means that Arabs should never speak the foreign word until it is accompanied to the structure of their speech, which might not happen.

Marwan Al-Mahasni says: "The Arabic language is one of the most compliant, flexible, and wider languages due to the various ways in creating words and terms which can be by root, figuration, Arabization or blending " (Al-Mahasni, the Arabic Language Academy). In many times, we use the scientific meanings in different structures and forms; if such forms were limited and easy, we can continue using them; however, if they were long, they should be blended to facilitate its use and proliferation, i.e. using blending is only in need when the scientific words are composed of many heavy words noticing that the live languages tend to make them short through having an equivalent for each scientific term in the Arabic language composed of one word with only one meaning.

We conclude that Arabic looks for all the capabilities and characteristics making them cope up with the flood of civilization and its knowledge and sciences; measuring in blending should be examined and used while taking into consideration the Arabic word weights and the harmony of its alphabet when being created.

There are many words which were widely used along with their counterparts in the language indicating that the language is flexible and has the ability of the absorption and translation among languages; it was not corrupted and it did not lose its identity; otherwise its fertility increased becoming a universal language of civilization and thought. (Khalifa, 1992). The Arabic language is greater and more accurate than the Semitic languages in the rules of grammar and more accurate in terms and words (Abidin, 1951); it is spoken by more than a billion Muslims, and it is a course taught in South Korean universities as a requirement of academic success.

\section{Signs of Distinguishing Between ARABiC AND ARABized TERmS}

There are many signs of distinguishing between the Arabic and Arabized words, most important of which are: (Zadah, 1983)

1. Translation: It is intended to get the foreign word to us by one of the Arabic language specialists by pointing out that this word is an Arabized foreign word.

2. The weight of the word comes in accordance with the weight of the Arabic words, such as: "Abrism" based on the weight "I'f'ay'il" and other words like, "telfizion, radio, and computer" which are all names of inventions not affecting the safety of the classical Arabic language.

3. A word starting with " $n$ " followed by "r", such as: "Narjis", which is not found in the Arabic word.

4. A word ending with a "z" followed by "d", such as: "Muhandis which is not found in the Arabic word.

5. A word having both "s" and "j", such as: "Solajan".

6. A word having both "q" and "j", such as: "Qayj" meaning Partridge, which is Persian.

Arabization is one of the important topics in the language for its increasing richness and ability for the fertile development. This topic has many aspects: relating to the Arabization of scientific terms, relating to the translation of 
the great international books of literature and thought into Arabic, and relating to the Arabization of the university education (Khalifa, 1992).

This requires from Arab linguists collect,prepare and analyze all the scientific, artistic, literary, and educational terminology as well as know their synonyms and definitions in the same language. This also requires from them collect the concepts related to a certain domain of knowledge, study the relationship between these concepts, and determine a particular term for the single concept by experienced specialists in translation and localization (Al Qasimi, 1980); there are blessed efforts in these scientific fields though they are individual and unorganized but efforts whose source is the publishing houses, so they are not issued by language academies or recognized Arab universities, which we seek and confirm to have.

There is no doubt that there are too many sciences, so therefore must be a great number of terminology to replace them (Al-Samarrai, 1977); Al-Shihabi pointed out that the terminology transfer rules lie in four things, namely: (AlShihabi, 1965)

1. altering the old linguistic meaning of the word.

2. Deriving new words from derived or Arabic origin to denote the new meaning.

3. translating foreign words with their meanings.

4. Arabicizing foreign words with their meanings.

It is obvious that the Arab scholars focus on the need to uphold with the morphological weights and the Arabic formulas for the word to be Arabized, making these standards a basis for Arabization, such as: derivation, blending and exchange, and finally focusing on paying attention to meaning more than the Arabizedword.

The desire to keep up with the times is the power than drives Arab researchers, language academies and patriotic and national institutions to develop scientific terms because the term is the search tool and the language of understanding among scientists, and an important part of the scientific method (Khalifa, 1992).

\section{The Arabic Language Keeping Pace with the Scientific DeVelopment and the EfForts of the ACAdemy OF THE ARABIC LANGUAGE}

It was natural that the Arabic language keeps pace with the other advanced languages without any laxity or negligence in the nature of language or its usual rules, accordingly, the Academy of the Arabic Language decided to adopt a specific scientific project so it can come out from theory into action. (Khalifa, 1992). Accordingly, the Arabic language faced its historical experience through absorbing the outcome of knowledge and sciences reached by man leading to establishing obvious rules and assets in the choice of language terms that indicate such scientific terms; the scientific heritage currently gives us large linguistic wealth which might be suitable to face the process of Arabization,

Many conferences were held for Arabizationin the Arab countries, such as Rabat, Baghdad, and Algeria, and many scientific seminars were held in the language academies and universities. Such conferences resulted in many researches; such as searching in different issues connected with the Arabization in its wide sense and they resulted with recommendations that were not followed, such as the fact that Arabization is an issue that is related with the basis of the political will of the country and the political decision made by the country at the top institutions of the authority.

The Arabic language faced the topic of the scientific terms for the first time in its history; the linguistic assets which stemmed from the nature and characteristics of the language that they enriched our language with life and made it a developed language that adopts with the civilization of the human and his culture. Accordingly, the derivation, metaphor, substitution, blending, and Arabization are some means for the growth of the language. In derivation, scientists have found a wide field for the development of the language and enriching it with scientific terminology; they were not limited to the derivation from the nouns of the meanings but they derived from the nouns of things; they said ("thahhab-made gold" from the noun "thahab-gold" and "gaddadah-made silver" from the noun "fiddah-silver". They also derived nouns from arabized names; for example, "handas-work in engineering" from "handasa-engineering" and "mantaqa-study in logics" from "almanteq- logic". (Khalifa, 1992).

The decision of the Academy of the Arabic language of Cairo to approve Arabization was final for the historical linguistic significance of the word of Arabization; however, the Arabized work must pass two important phases, namely:

First: the linguistic phase reached to by the knowledge explosion of the world in the second half of the twentieth century, i.e. after the Arabic language was used in various branches of knowledge (Al-Jalili, 1984).

Second: the national phase, which is the latest development for the significance of the arabization language making the Arabic language a thinking and a writing tool that is used in the Arabic social, economic, scientific, literary, and educational life to get rid of dependence and keep abreast of development (Al-Khatabi, 1973).

this imposes a significant role for the leagues that the Jordan Academy of Arabic called for facing and cutting the road for those calling for educating sciences in a foreign language with the plea that there are no books in Arabic regarding this and that the Arabic language is not the language of science and civilization. (Khalifa, 1992). Therefore, the academy started the Arabization of scientific books that are taught in the first year at the Faculty of Science at the Jordanian universities; the academy of the Arabic language has established the scientific foundation to enrich the Arabic language with both the scientific and technical terminology making it stand on an equal footing with the language of science in the world." 
In order to develop the Arabization of the university education, it is important to Arabicize the scientific terms, foreign periodicals, mothers of sources, and scientific references placed in foreign languages (Khalifa, 1992) since the scientific research and inventions add tens of words to the human knowledge; accordingly, we see that we have no choice except to begin exercise the Arabization movement in its various fields; strengthening this facilitates us to overcome the obstacles that traversed modern nations whose national languages did not have the available reasons found in the characteristics of the Arabic language; accordingly, large efforts should be done among the joint Arab action institutions dealing with Arabization (Khalifa, 1992).

\section{CONCLUSION}

After this review of the importance of the Arabic language in deepening the national and Islamic identity, in terms of the language of the Koran through history, generations and eras in all fields and levels, the present study discussed the most important issues and problems facing the Arabic language in the modern era, which is represented in Arabization; the study concluded the following most prominent results:

1. Arabization is an ancient linguistic phenomenon in our Arabic literature since the era of ignorance through the Islamic Ages right down to the present era given the geographic, economic, and political circumstances; there are words that entered into Arabic in the era of ignorance by those circumstances, such as: "filfil" from the Persian language and "tanour" form the Roman language.

2. The process of Arabization is an imperative and indispensable human need in order to meet the scientific, economic, political, military, literary and other fields; it has linguistic, scientific, and civilized benefits.

3. The process of Arabization is a linguistic license, used by researchers, scholars and translatorswhen there is no Arabic eloquent word giving the meaning and significance of the foreign word, such as: "computer" which has no equivalent in Arabic according to its weight, so it was arabized to "hasub", which is a machine name at the weight of (fa'ul); other examples include: "'l-shakoush" and "'l-satur".

4. the Arabic language used means and images of Arabization now and then to indicate the Arabized terms, including: linguistic borrowing, figurative translation, blending and derivation.

5. There are some obstacles facing the process of Arabization among which is the different methods and techniques of Arabization in the Arab countries, especially in the university education; there are significant efforts for the language academies in Jordan, and Syria in the Arabization of a lot of sciences that are still taught in foreign languages in some Arab countries for strengthening students and enabling them to master such foreign languages, which is a weak argument and it has a risk to the national and religious identity in the future.

6. our holy Arabic language faces risks that may result from the expansion of the Arabization, such as: the foreign words' competition with the classical Arabic, the loss of the expressive value of the Arabicroot, breachingthe morphological rules, and the ambiguity of the meaning of the Arabized words in our Arabic dictionaries.

7. the Arabization process can achieve its desired objectives in the scientific development if the faithful experienced in this area were available along with specialized colleges and institutions in this area in accordance with, and within the agreed criteria by the Arab language academies.

8. the study pointed out to the proofs through which we can distinguish between the authentic Arabic words and the Arabized, such as translating by one of the Arabic linguists by pointing out that this foreign word is arabized, the deviation of the morphological weight from the Arabic weights, in addition to the fact that its start should be " $n$ " tehn "r", its final should be "z" then "d", combing both "s" and "j" and combing both "q" and "j" in one word.

9. The study also identified the conditions and criteria that must be followed to translate scientific terms, including: the presence of a precise semantic relationship between the original meaning and the new meaning, one word to denote a particular term, a new term agreed between Arab linguists, and avoid words difficult Copyright pronunciation that alienate them, or meaningful concern flip-flops.

10. The study pointed out to the role of Jordan through its language academy in Arabizing the university scientific education at Yarmouk University and University of Jordan. The success in such scientific faculties increased, which indicates that this experiment is successful and we hope that it is applied in the rest of the Jordanian and other Arab universities.

\section{RECOMMENDATIONS}

At the conclusion of this study, the researcher can provide the following recommendations:

1. allocating specific scientific colleges and institutes for the training of translators on Arabizing scientific terms, and others.

2. Identifying agreed upon Arabic standards among Arab language academies to carry out the Arabization process by all the international languages and translating the terms of its modern scientific innovations.

3. circulating successful experiences in the field of arabization, which are done by the official institutions and Arab universities on the rest of the Arab world institutions and publishing them to make the work unified and collective.

4. Strengthening the role of the media in translating and publishing the era innovations and submitting them to researchers in facilitated methods. 
5. facilitating and supporting the efforts of translators to get to the sources, references, and foreign and Arabic periodicals, which are interested in the process of Arabization by researchers, scholars, and specialists.

6. I recommend researchers, and those caretakers responsible for the country institutions, in particular, those with the greatest impact in the development and modernization of the Arabic language being the language of the Koran and having a sacred place in the hearts of millions of Muslims.

\section{REFERENCES}

[1] Abidin, A. (1951). Introduction into the Study of the Arabic Grammar in the Light of Semitic Languages, AlShakshaki Press, Egypt.

[2] Al-Bustani, B. (1995). Modern Arabic Language, Lebanon Library, Beirut.

[3] Al-Daqiqi, S. (1985). Same Structure and Different Meanings, examined by Abd Al-Rauf Jabr, Ammar house of Publishing and Distribution.

[4] Al-Jalili, M. (1984). Experiments in Arabization, Jordanian Academy of the Arabic Language, Amman.

[5] Al-Jawhari, M. (1980). The Language Crown and the Arabic Sahah, examined by Ahmad Abd Al-Ghafoor Attar, Science for millions house of publishing, Beirut.

[6] Al-Jawliqi, A. (1995). the Arabized Words of Foreign Speech on the Dictionary Letters, examined by Ahmad Shaker, the Egyptian National Library, Cairo.

[7] Al-Khitabi, M. (1973). Arabic as a Mother Language, Journal of the Arabic Tongue, 10 (2), 23-31

[8] Al-Malaika, J. (1988). Scientific Term Requirements, the Iraqi Academy journal, 24 (3), 123 - 141.

[9] Al-Moosa, N. (1985). Blending in the Arabic Language, Al-Oloum house of printing and publishing, Riyadh.

[10] Al-Mahasni, M. (2009). the Arabic Language Academy, the Journal of the Arab tongue, 62 (2), 11- 33.

[11] Al-Mubarak, M. (1989). Philology and Arabic Properties, Beirut, Al-Fikr house of publishing.

[12] Al-Muzhir , C. (1986). Language Kinds and Sciences, Modern Library, Beirut.

[13] Al-Qasimi, A. (2004). Borrowing and Arabization in the Generation of Scientific Terminology, Research published in the symposium of term and terminology, Algeria.

[14] Al Qasimi, A. (1980). Terminology: The General Theory for the Development, Standardization and Documentation of Terms, the Arab Tongue Journal, 18 (1), 44- 61.

[15] Al Qasimi, A. (1986). the Unified Term and its Status in the Arab World, the Journal of the Arabic tongue, 27 (2), 1-19.

[16] Al-Saleh, S. (2004). Studies in Philology, Science for millions house of publishing, Beirut.

[17] Al-Samarrai, I. (1982). Arabic Faces the Current Era, Al-Jahigh house of publication, Baghdad, .

[18] Al-Samarrai, I. (1977). Language and Culture, the Arab Association for Studies and Publishing, Beirut.

[19] Al-Shihabi, A. (1965). Scientific Terminology in Arabic Now and in the past, high-Arab Studies Institute.

[20] Al-Thaalbi, A. (1999). Philology and Secrets of the Arabic Language, Modern Library, Sida.

[21] Al-Tunaji, M. (2005). Persian Dictionary of Arabized Words, Lebanon Library, Beirut.

[22] Al-zarkan, A. (1988). Linguistic Efforts in the Modern Scientific Term, publications of the Arab Writers Union, Damascus.

[23] Anis, I.( 1985). Al-Waseet Dictionary, part 2, the Revival of Arab Heritage House of Publishing, Beirut.

[24] Essa, A. (1923). Civility in the Assets of Arabization Now and in the Past, Arab Thought House of Publishing, Cairo.

[25] Faisal, S. (1986). Arabic Contemporary Issues, the Arabic tongue journal, 26 (1), 35- 49.

[26] Ghaneim, K. (2014). Arabization Mechanisms and New Industry Terminology, the Palestinian Arabic Language Academy, Gaza.

[27] Ghaneim, K. (1989). the Arabic Language and the Modern Scientific Awakening, Ibn Sina Library for Publishing and Distribution, Cairo.

[28] Ghazal, A. (1977). General Methodology for Arabization, the Institute of Studies and Research of Arabization, Rabat.

[29] Hassan, A. (1966). Language and Grammar, Al-Maaref House of publishing, Egypt.

[30] Hebu, A. (1990). Foreign Words in Arabic Before Islam, Aleppo University Research Journal, 19 (1), 22-38.

[31] Ibrahim, M. (1994). the Arabization of Higher Education, Afaq House of Publishing, Amman.

[32] Khalifa, A. (1992). the Arabic language and Arabization in the Modern Era, Al-Furqan house of publishing, Amman.

[33] Kharyosh, A. (2003). Arabization Movement in Jordan, the Ministry of Culture, Amman.

[34] Sibawayh, S. (1983). investigated and explained by Abd Al-salam Haron, Beirut, the world of books.

[35] Wafi, A. (2004). Philology, the Renaissance of Egypt, Cairo.

[36] Wafi A. (2010). Linguistics, the renaissance of Egypt, Cairo.

[37] Zadeh, A. (1983). in Rounding, examined by Ahmad Khattab, Mosul University.

[38] Zubaidi, M. (1994). Bride's Crown of the Dictionary Jewels, examined by Ali Al-Sharayri, Al-Fikr house of publishing, Beirut.

Abeer Obeid Al-Shbiel was born in Mafraq, Jordan, in 1978. She finished her PhD in Applied linguistics from Yarmouk University, Jordan in 2009. She is currently an Assistant Professor in Irbid University College - Al-Balqa Applied University (BAU). 